\title{
The organization of children's secure base behaviour in two-parent Portuguese families and father's participation in child-related activities
}

\author{
Lígia Monteiro \\ Auburn University, Auburn, Alabama, USA \\ Manuela Veríssimo \\ Unidade de Investigașão em Psicologia Cognitiva do Desenvolvimento e da \\ Educação, Lisboa, Portugal \\ Brian E. Vaughn \\ Auburn University, Auburn, Alabama, USA

\begin{abstract}
António J. Santos, Nuno Torres and Marília Fernandes Unidade de Investigação em Psicologia Cognitiva do Desenvolvimento e da Educação, Lisboa, Portugal
\end{abstract}

\begin{abstract}
The organization of children's secure base behaviour was studied in twoparent Portuguese families, with 44 father-child and mother-child dyads, children's age was on average 31.91 months. An analysis of Attachment Q-sort (AQS; Waters, 1995) data revealed no significant differences in security scores for mothers and fathers. Both parents independently responded to a questionnaire about their participation in child-related activities, relative to their spouse's participation in these activities. A traditional division in the Care/Organization tasks and a shared participation in the Play/Leisure activities emerged. Fathers with higher scores for both types of activities tended to have children with higher security scores. Fathers' participation in Play/Leisure activities was associated with children's AQS scores with their mothers. In this sample father's participation is
\end{abstract}

\footnotetext{
Correspondence should be addressed to Manuela Veríssimo, Rua Jardim do Tabaco, 34, 1149 - 041 Lisboa, Portugal. E-mail: mveriss@ispa.pt

This work was supported in part by grant s from FCT (PTDC/PSI/66172/2006) and NSF (BCS 0623019).

The authors wish to thank all the mothers, fathers and children who participate in this study. We are also grateful to all the colleagues from Line 1 of UIPCDE - Developmental Psychology for their valuable comments.
}

(C) 2009 Psychology Press, an imprint of the Taylor \& Francis Group, an Informa business http://www.psypress.com/edp

DOI: $10.1080 / 17405620902823855$ 


\section{6}

positively associated with the quality of secure base relationships within the family context.

Keywords: Family context; Fathers' participation; Secure base relationships; Type of activities.

Attachment theory highlights the role of social transactions in both the construction of the relationship and its quality (Ainsworth, Blehar, Waters, \& Wall, 1978; Bowlby, 1988; Marvin \& Britner, 1999). The child organizes her/his behaviour around the figures with whom she/he interacts on a regular basis and these figures tend to become more salient as interaction experiences accumulate (Ainsworth, 1967; Bowlby, 1969/1982; Schaffer \& Emerson, 1964). In studies of mothers and children, these transactions have often emphasized routine caregiving/nurturance (e.g., feeding, bathing, teaching) to a greater extent than playful interactions. However, when fathers and children are studied, play interactions are often given greater emphasis, reflecting a stereotype concerning interaction domains preferred by fathers (e.g., Bowlby, 1969/1982, 1988; Grossmann et al., 2002; Lamb \& Lewis, 2004). We note, however, that this stereotype is not necessarily confirmed in all cultures (e.g., Lamb, 1987). Irrespective of the interaction context studied most often for mothers or for fathers, most studies have shown that the child's transactions with either parent do serve to support the co-construction of attachment relationships (e.g., Caldera, 2004; Grossman et al., 2002; Lamb, 1977, Main \& Weston, 1981; Monteiro, Veríssimo, Vaughn, Santos, \& Fernandes, 2008).

Interest in the father's role in child development, as well as his influence in the family context, has increased significantly over the last 30 years as a consequence of the contemporary economic, social and cultural climate. While contemporaneous women are taking responsibilities in both the domestic and the broader economic spheres, a new image of men emphasizing a caring father, who is actively engaged in the daily lives of his children and sharing responsibilities and tasks in a more egalitarian way across economic, domestic and child-care spheres, is emerging (e.g., Balancho, 2004; Cabrera, Tamis-LeMonda, Bradley, Hofferth, \& Lamb, 2000; Deutsch, 2001; Lamb, Frodi, Hwang, \& Frodi, 1983; Parke, 1996). Data suggest that although, at this point in history, some men are behaving differently from fathers in previous generations, and even from some of their peers, this change may be more modest than conveyed by the popular media (Lamb \& Tamis-Lemonda, 2004; Parke, 1996; Pleck \& Masciadrelli, 2004). This seems also to be true in Portugal, a European Union (EU) country with one of the highest percentages of women in the labour force, particularly for those with preschool-age children (e.g., Amâncio \& Wall, 2004; Monteiro, Veríssimo, Castro, \& Oliveira, 2006; Torres, 2004). 
There is little theoretical or empirical work linking the quantity of father involvement to the development of attachment relationships (Brown, McBride, Shin, \& Bost, 2007; Lamb \& Tamis-LeMonda, 2004). Nonetheless the assembly of secure base relationships during infant and toddler years requires numerous behavioural transactions between the attached child and the attachment figure over an extended period of time. When the father is an active participant in the child's daily activities/routines, the child-father secure base relationship seems to benefit, suggesting that child-care experiences may facilitate the way fathers interpret and respond to their child's signals (Donate-Bartfield, \& Passman, 1985; Frascarolo-Moutinot, 1994, cited in Lamb \& Lewis, 2004). Even if the father has the capacity to be sensitive to the child's communicative signals, this capacity may not be exercised when fathers and their children interact only infrequently (e.g., Cox, Owen, Henderson, \& Margand, 1992).

Lamb et al. (1983) suggested that the quality of the child-father relationship may be associated with a particular type of involvement (i.e., in play, instead of being associated with a global quantity of involvement) and they argued that play interactions (when characteristically distinctive from mother-child play patterns) may increase fathers' salience for the child. Children's positive affect may, in turn, promote the development of more meaningful father-child dyadic interactions, even when fathers participate less often in other child-care contexts. Easterbrooks and Goldberg (1984) reported that paternal participation in child-care tasks was not associated with attachment quality, in a sample of toddlers, but the amount of time that fathers spent playing and the amount of time alone with the child did contribute uniquely to child outcomes. On the other hand, Caldera (2004) found that when fathers had higher levels of engagement in caregiving (e.g., change nappies, bathing), their infants had higher security scores (Attachment Q-set by father self-reports), whereas this association was not observed for fathers' engagement in play/reading activities. Finally, Cox et al. (1992) observed that quality of interaction (i.e., the more positive, playful and physically affectionate the father was), but not the quantity of time he spent with the child predicted security of the child-father attachment.

Easterbrooks and Goldberg (1984) reported that father involvement (quantity of time spent with the child) contributed uniquely to child development, independent of associations with the quality of parenting behaviours (although quality also explained a significant proportion of outcome variance), but parent involvement and parenting characteristics simultaneously accounted for a larger proportion of the outcome variance, than either set of characteristics alone. Brown et al. (2007) reported that fathers' parenting quality and involvement (i.e., quantity) had interactive 
effects on child-father attachment relationship. For fathers exhibiting positive parenting behaviours, their degree of engagement did not significantly predict attachment security. However, lower quality of parenting combined with high involvement had a cumulative negative impact on attachment security (with the father) for the 2-and 3-year-olds in their study. Although the available studies do not yield clear or consistent results about the attachment-relevant effects of fathers' participation in child-rearing activities, some empirical data seem to suggest that the father's level of involvement may have an impact (positive or negative) on childfather secure base relationship.

The present study aimed to examine secure base relationships within the family by observing the organization of the child's secure base behaviour around both parents at home (see Posada, Waters, Crowell, \& Lay, 1995b, for a rationale for assessing attachment organization in "ordinary" circumstances and settings). Because the attachment data were collected using the Attachment Q-sort (AQS; Waters, 1995), it was possible to perform analyses at the level of global "security" (Waters, 1995) and also at the level of Q-sort subscales (Posada et al., 1995b), to determine whether the full range of content relevant to secure base behaviour is similar or different for fathers and mothers. The second major aim of the study was to consider child-secure-base organization in relation to the degree of parent participation in two crucial child-rearing domains: routine care/nurturance/ organization of time and life space versus play and leisure activities. Mothers in this sample worked full time (an important sociodemographic predictor of father involvement), and their children (between 2.5 and 3 years of age) attended day-care centres several hours a day. Thus, we were interested in knowing whether the relative degree of sharing tasks in the two abovereferenced domains would predict child secure base behaviour (i.e., attachment security) with the father.

Fathers may have an impact on their children's development, both directly by means of interaction and indirectly by virtue of their impact (positive and negative) on the family's social and emotional climate (see Lamb, 2004). According to Bowlby (2002), fathers may adopt a supportive role, emotionally and instrumentally, for the mother, which contributes to their children's healthy development. Goossens (1987) reported that when fathers' participation in caregiving and play activities, in dual-earner families, was characterized as more egalitarian, mothers felt more supported, and father participation was associated with child-mother attachment classifications in the strange situation (Ainsworth et al., 1978). So, we assessed father's participation in activities related to Care/Organization and Play/Leisure activities and the possible associations with children's organization of secure base behaviour with the mother. 


\section{METHOD}

\section{Participants}

Forty-four father-child and mother-child dyads from bi-parental families participated in the study. Children were between 29 and 38 months of age $(M=31.75 ; S D=2.56)$, all of European descent, 23 were girls and 21 were male, 24 were firstborn and 31 had siblings. The children entered nonparental childcare between 4 and 30 months $(M=8.67, S D=6.59)$ and they spent from 3 to 10 hours $(M=7.56 ; S D=1.53)$ in non-parental care each weekday. This large range in hours spent in non-parental care is explained by the common practice in Portugal for grandparents to pick up children from school before parents get home from work. The range of mothers' ages was 26 to 48 years $(M=34.95 ; S D=4.33)$ and fathers' ages ranged from 28 to 63 years $(M=37.48 ; S D=6.08)$. Mothers' education level varied between 7 and 23 years $(M=15.46 ; S D=3.34)$ and fathers' varied between 7 and 23 years $(M=14.77 ; S D=3.17)$. Both parents were employed full time. All families were "middle class" in terms of income level, according to the standards of the local community and most had education levels and job titles characteristic of "middle-class" status. The children attended private day-care programmes in the suburbs of Lisbon, Portugal, where families were recruited, to participate in a larger longitudinal study that assesses socioemotional development during the pre-school years. The recruitment rate for this project was about $90 \%$ for mothers and $75 \%$ for fathers. For this study, we only report data for families where both parents agreed to participate.

\section{Instruments}

Attachment Behaviour Q-Set (AQS, Waters, 1995). The AQS measures the organization of the child secure base behaviour in the presence of the mother, or other attachment figure, in ecologically valid contexts (Vaughn \& Waters, 1990). The secure base behaviour is characterized in terms of its organization in these contexts (Posada et al., 1995a). The AQS provides a detailed description of the child's attachment behaviour and has been used to document both changes and continuities in the development of attachment relationships (Veríssimo, Blicharsky, Strayer, \& Santos, 1995). Furthermore, the AQS is particularly useful when multiple assessments are planned, because most children do not become sensitized to the observers during the home observations (van IJzendoorn, Vereijken, BakermansKranenburg, \& Riksen-Walraven, 2004; Waters \& Deane, 1985). Observers complete the AQS by distributing the 90 items into 9 categories, according to a fixed distribution. After a period of observation (a minimum of 2 hours) of each child, the observer sorts the AQS items into the 9 categories that 
range from "extremely characteristic" to "extremely uncharacteristic". Placement of an item in the distribution is determined by the salience/ relevance of the item as observed, rather than by frequency or visibility of the described behaviour per se. Items that are more characteristic of the child are placed in the higher categories (9-7) and items that are less characteristic, or very uncharacteristic, of the child are placed in the lower categories (1-3). Items that are neither characteristic nor uncharacteristic or items that are not observed in the time frame of the observation should be placed in the centre of the distribution (categories 6-4). In order to obtain a final score, the Q-description of the observed child is compared to a "criterion sort" described by Waters (1995). Individual cases are compared with this criterion by correlating the vector of item scores derived from the sort of an observed child with the vector of criterion item scores. This correlation value indexes the similarity of the "observed child" to the idealized hypothetical child, and ranges (theoretically) from -1.0 to 1.0. In practice, scores below -0.25 or above 0.80 are rare. The validity of the AQS using observers, but not self-reported, has been clearly confirmed in a meta-analysis by van IJzendoorn et al. (2004), and it was included in the same category, in terms of quality, as that of the Strange Situation and the Adult Attachment Interview. Previous studies with Portuguese samples supported the validity and usefulness of the AQS for Portuguese culture (e.g., Monteiro et al., 2008; Veríssimo, Monteiro, Vaughn, Santos, \& Waters, 2005).

AQS subscales. Posada et al. (1995b) identified subsets of items from the AQS that were face-valid indicators of secure base behaviour and sociability and arranged these items into four Q-sort subscales: Smooth Interaction with Caregiver; Proximity to the Caregiver; Physical contact with the Caregiver; and Interaction with Other Adults. In the present study, the fourth subscale is not used in the analyses, because this scale seems to reflect temperamental sociability rather than secure base behaviour. Cronbach's alpha for the subscales ranged from .78 to $.92(M=.85)$ for the AQS with the father; and from .78 to $.90(M=.85)$ for the AQS with the mother. These are acceptable levels of reliability and are comparable to those reported by Posada et al. (1995b).

Participation in child-related tasks. Parental participation was assessed using a questionnaire (Monteiro et al., 2006), with 17 items related to the organization and the realization of different activities with the child, occurring in the context of the family's daily life. The items are summarized by two dimensions: (1) Care/Organization tasks (11 items), related to the organization and the undertaking of childcare activities (e.g., "Who feeds the child" or "Who buys the child's cloths"); and (2) Play/Leisure activities 
(6 items) related to play and leisure (e.g., "Who reads stories to the child" or "Who takes the child to the playground"). Cronbach's alpha for the Care/ Organization tasks were .68 and .70; and for the Play/Leisure activities were .84 and .70 , for fathers and mothers respectively. Participation was assessed relative to the degree of participation of the spouse and the score represents the respondent's perception of the division/sharing of activities between both parents. Participants were asked to answer using a 5-point scale: (1) Always the mother; (2) Nearly always the mother; (3) Both the mother and the father; (4) Nearly always the father; and (5) Always the father. Thus, scores do not reflect an absolute quantity of parental engagement in child care, but rather the balance of care between both parents. Higher scores suggest greater father involvement and lower scores suggest greater maternal responsibility for child rearing.

\section{Procedures}

Home visits. Father-child and mother-child dyads were observed during separate visits, each lasting between 2 and 3 hours. During the observations of the mother-child dyad, the father was asked not be present (mothers were also asked to absent themselves during the father-child observation). Home visits were counterbalanced (thus, for approximately half the families, fathers were observed first). The average interval between the visits was one month. The parents were told that the purpose of the visit was to better understand the child and the parent in their daily routine and experiences, for which reason they were asked to keep their daily activities unaltered as much as possible, in spite of the observers' presence. No other special restrictions were enforced during dyadic observations. Two observers were present for all home visits, and they behaved as social visitors in the home, not intervening in family routines, but participating in play if invited by the child. They talked informally with the parent, but tried not to interfere with child-parent interactions. When it was opportune and in the sequence of the conversation with the parent, observers asked questions concerning AQS items that could not be observed (e.g., item 10 refers to the child's behaviour when he/she goes to bed) and about items they may not have observed during the visit (e.g., item 45 refers to the child's liking to sing and dance to music). Different teams of observers completed home visits for fathers and mothers. At the end of each visit, the two observers independently sorted the AQS items as described above. Observers were trained over a period of several weeks before initiating formal observations for the project. After training, inter-observer agreement (Q-correlation) was between .60 and .89. Rater agreements during actual data collection were .73 for the fathers, and .72 for the mothers. The Q-sort for the child was a composite (average) of the two Q-descriptions provided by each observer. 
Parental reports. The 17-item parent participation questionnaires were delivered to the mothers and fathers at the end of the home visit, and completed independently by them.

\section{RESULTS}

\section{Secure base behaviours with fathers and mothers}

Preliminary analyses tested the relations between sociodemographic variables (i.e., age, years of education, number of months the child was enrolled in day care prior to assessment, gender of the child) and the AQS security scores for both parents. No significant associations were found for fathers' and mothers' security scores.

AQS security scores. The AQS security scores for fathers ranged between -.04 and .79 , with a mean of $.41(S D=0.20)$. The AQS security scores for mothers ranged between -.12 and .79 , with a mean of .45 $(S D=0.21)$. These values are within the range of typical values identified by van IJzendoorn et al. (2004) in their meta-analysis of studies using the AQS in non-clinical samples. Within-subject ANOVAs grouped by child gender tested differences between the AQS scores for fathers versus mothers. Neither the main effects nor the parent by gender of child interaction reached statistical significance. These results are consistent with the literature on child attachments to both parents (e.g., Caldera, 2004; Frosch, Mangelsdorf, \& McHale, 2000; Main \& Weston, 1981).

AQS subscale scores. Within-subjects ANOVAs with child gender as a between-subjects factor tested for mean differences on the Q-sort subscale scores. The results are presented in Table 1. Mothers had higher scores than fathers for the Proximity and Physical Contact subscales, indicating that items describing the child's proximity seeking and contact maintenance were more salient to observers when the child was seen with her/his mother than

TABLE 1

Means and standard deviations of the AQS scales for mothers and fathers

\begin{tabular}{lcccccc}
\hline & Father & & Mother & & & \\
\cline { 2 - 2 } Subscales & Mean $(S D)$ & & Mean $(S D)$ & F-value $(1,110)$ & $\eta$ & $r_{\text {father } \times \text { mother }}$ \\
\hline Smooth interaction & $6.32(1.02)$ & & $6.44(1.22)$ & 0.30 & .00 & $.29^{*}$ \\
Proximity & $5.08(1.09)$ & & $5.63(1.14)$ & $6.63^{* *}$ & .042 & $.49^{* *}$ \\
Physical Contact & $6.13(1.28)$ & & $6.59(1.11)$ & $4.12^{*}$ & .038 & .19 \\
\hline
\end{tabular}

Note: ${ }^{*} p<.05 ; * * p<.01$. 
when observed with her/his father. Neither the main effects of child gender nor the parent by child gender interactions were statistically significant. No effects for the Smooth Interaction scale were significant.

Correlations between the AQS scores for fathers and mothers are also presented in Table 1. Significant correlations between fathers and mothers were found for the Smooth Interaction and Proximity subscales. Although children tended to stay in closer physical proximity/contact with their mothers than with their fathers, children with higher subscale scores with one parent tended to have higher scores with the other parent as well. We also examined associations between the AQS subscales and the AQS security score with fathers and mothers (see Table 2). AQS security was significantly associated with each of the secure base scales for both fathers and mothers. Furthermore, the pattern of correlations was similar for both parents.

\section{Analysis of participation in child-related activities}

Agreement in parental reports. Because the data were obtained independently it was possible to analyse the level of agreement in parental reports, the Pearson correlation for the Care/Organization tasks was $r=.97$, and $r=.98$, for Play/Leisure activities, $p<.001$ for both. These results are consistent with the conclusions reached by Pleck and Masciadrelli (2004), who suggested that fathers' reports concerning involvement in parenting have validity relative to mothers' reports. Due to the high agreement between fathers' and mothers' assessments we used the parental mean score in the following analyses.

Type of activities. On average, both parents agreed that the Care/ Organization tasks were mostly the responsibility of mothers $(M=2.18$, $S D=0.39)$ and that both the mother and the father participated in Play/ Leisure activities $(M=2.70, S D=0.32)$. A paired-sample $t$-test comparing mean scores for the two scales was significant, $t(43)=10.1, p<.001$. Parents agreed that fathers were more involved in activities listed on the Play/ Leisure scale than in activities listed in the Care/Organization scale.

TABLE 2

Correlations between security scores for mothers and fathers and the AQS subscales

\begin{tabular}{lccc}
\hline & Smooth interaction & Proximity & Physical contact \\
\hline Security score: father & $.85^{* *}$ & $.48^{* *}$ & $.49^{* *}$ \\
Security score: mother & $.87^{* *}$ & $.40^{* *}$ & $.39^{* *}$ \\
\hline
\end{tabular}

Note: ${ }^{*} p<.05 ; * * p<.01$. 


\section{MONTEIRO ET AL.}

Sociodemographic variables. The association between sociodemographic variables and the participation in the two types of activities was analysed using Pearson correlations (see Table 3 ). The only significant correlation was between Play/Leisure activities and fathers' years of education. Fathers' education level was positively associated with his involvement in play and leisure activities. ANOVAs did not reveal any significant differences in paternal participation for girls and boys, or for birth order.

\section{Fathers' participation and the organization of secure base behaviours in child-father dyads}

AQS attachment security in the father-child dyads was positively and significantly associated with the fathers' participation in the Care/ Organization tasks $(r=.44, p<.01)$, while the association with the Play/ Leisure activities was marginally significant $(r=.26, p<.08)$. Parental participation scores were also correlated with the AQS subscales. These results are presented in Table 4. The Proximity and Physical contact subscales were positively and significantly correlated with both the

TABLE 3

Correlations between sociodemographic variables and participation in types of activities

\begin{tabular}{lcc}
\hline & $\begin{array}{c}\text { Care/ } \\
\text { organization } \\
\text { tasks }\end{array}$ & $\begin{array}{c}\text { Play/ } \\
\text { leisure } \\
\text { activities }\end{array}$ \\
\hline Child's age & .07 & -.11 \\
Mother's age & .14 & -.12 \\
Father's age & .16 & -.12 \\
Years of education: mothers & .17 & .18 \\
Years of education: fathers & .12 & $.40^{* *}$ \\
Year of entrance in non-maternal care & -.12 & .04 \\
Number of hours in the day-care/day & .32 & .02 \\
\hline
\end{tabular}

Note: ${ }^{* *} p<.01$.

TABLE 4

Correlations of type of activities with AQS subscales in fatherchild dyad

\begin{tabular}{lccc}
\hline & $\begin{array}{c}\text { Smooth } \\
\text { interaction }\end{array}$ & Proximity & $\begin{array}{c}\text { Physical } \\
\text { contact }\end{array}$ \\
\hline Care/organization tasks & .26 & $.37^{* *}$ & $.45^{* *}$ \\
Play/leisure activities & .06 & $.36^{*}$ & $.35^{*}$ \\
\hline
\end{tabular}

Note: $* p<.05 ; * p<.01$. 
Care/Organization and Play/Leisure scales. That is, when fathers increased their involvement, scales reflecting secure base behaviour also increased in the AQS subscales. A marginally significant association was found for Smooth Interaction and the Care/Organization scale $(p<.08)$.

\section{Parental shared participation and the organization of secure base behaviours of the child-mother dyads}

The last set of correlations considered the possible associations between parental activity participation and the AQS scores from child-mother observations. The AQS security score was significantly associated with the degree of sharing for Play/Leisure activities, $r=.32, p<.05$. No other correlation reached significance.

\section{DISCUSSION}

Sociodemographic, cultural, economic and historical changes have had a substantial effect on how families organize themselves, as well as on popular and scholarly conceptions of children, parenting, and families (Cabrera et al., 2000; Lamb, 2004). In this study we examined the organization of secure base relationships in the family context, looking at the traditional versus shared parental participation in child-related activities and how the balance of parental participation may be related to attachment security.

We found that children use both parents as secure base (e.g., Bowlby, 1969/1982; Lamb, 1977; Monteiro et al., 2008) and that the security scores for fathers (.41) and mothers (.45) were not significantly different. Mean AQS scores for both mother and father were consistent with the notion that the majority of parent-child attachments are secure. These findings also support the idea that the child's use of attachment figures as a secure base for exploration remains an essential feature of the organization of children's behaviours during the second and third years of life (Bowlby, 1969/1982; Marvin \& Britner, 1999).

The data suggest that, for both parents, behaviours indexing three aspects of secure base content (i.e., Smooth Interaction, Proximity and Physical Contact) are significantly correlated with the AQS security scores. The child's relationship with each parent is marked by harmonious and warm communications, positive emotional tone, reciprocity and mutuality in the context of interaction, suggesting balanced and satisfying relationship that supports the child's exploration within the home. At the same time, exploration is balanced with proximity seeking (e.g., returning to the caregiver periodically, staying near her and/or keeping track of her location which allows the child to move away to explore the environment, knowing that she/he will be able to return to the parent if upset, bored or 
in need of help and that she/he will be welcomed and comforted). Significant between-parent differences were also found. Behaviours indexing Proximity and Physical Contact were more salient in motherchild interactions, as observed at home. According to attachment theory, different behaviours shown by different caregivers may serve a similar function, that is to respond promptly and appropriately to the child communicative signals. Even for the same caregiver behaviours will vary according to situations and contexts, but the results for the child will be the same. From the child's point of view, what is important is that he/she learns that the parent is responsive, co-operative, and available as needed (Posada et al., 1999).

As mothers' participation in the labour force has increased, family researchers have assessed fathers and whether they were shifting their level of involvement in child rearing, to alleviate the burdens of employed mothers. Looking at aspects of families' ecologies may help us to understand our results. We looked at the degree of fathers' shared participation in their children's lives. Since we asked both parents to describe their level of participation independently, it was possible to assess whether they had a shared perception of their responsibilities and participation in child-related activities. The very high correlation values obtained suggest that parents see their own and their spouse's level of participation similarly. Our results are consistent with previous studies with Portuguese preschool children (e.g., Monteiro et al., 2006), insofar as no effects of child gender on fathers' type or level of participation were significant. This finding is also consistent with a broader review of the father-involvement literature (Pleck \& Masciadrelli, 2004). Analyses of sociodemographic correlates of father involvement indicates that fathers with higher education tended to take a larger role in Play/Leisure activities than less-educated fathers, again, consistent with data reported for other Portuguese samples (e.g., Monteiro et al., 2006; Torres, 2004). Although all the mothers in this sample work full time, they remain the primary caregivers, since it was nearly always the mother who performed the Care/ Organization tasks, while the father tended to assume a more supportive role, probably helping only when needed, or when they were available. In Play/Leisure activities both the mother and the father participated but even for this category couples did not, on average, share these activities equally (see also Lamb \& Lewis, 2004; Monteiro et al., 2006; Peitz, Fthenakis, \& Kalicki, 2001; Pleck \& Masciadrelli, 2004, for similar findings). Nevertheless, fathers' involvement is significantly greater for play/leisure activities than for routine care and nurturance, which suggests that fathers find playful activities more appealing. It should be noted that even with this relatively small sample we found variations among fathers' levels of participation. Some fathers did take on co-parenting, sharing the various 
tasks equally with the mothers, while others conformed to the "absent father" stereotype, having a very limited participation in the activities covered in the questionnaire that we used.

Fathers' involvement has been associated with direct and indirect benefits for the child (Lamb \& Lewis 2004; Parke, 1996). In this study, we looked at secure base behaviour with both parents. Our results suggest that fathers who share the care/organization activities with their wives more equally have children with higher security scores in the AQS when observed at home with their father. AQS security scores for father-child observations also had a marginally significant association with the Play/Leisure scale. These findings are congruent with Caldera's (2004) study using the AQS (as a self-report), indicating that fathers who participate more in care tasks, but not in play/ reading activities, described their children as more securely attached. Focusing on specific behavioural domains tapped by the AQS, the associations between fathers' participation and the AQS Proximity and Physical Contact subscales were significant for both involvement scales, and Smooth Interaction was marginally associated with the Care/Organization scale score. These results are consistent with our suggestion that father involvement supports a positive co-construction of secure base behaviour for the child. This may suggest that child-care experiences, or participation in wider contexts and activities with the child, may facilitate the way fathers interpret and respond to their child's signals.

The findings discussed thus far concern the direct effect of father involvement on child secure base organization (with the father). A number of reviewers (e.g., Belsky, 1984; Bowlby, 2002; Lamb \& Lewis, 2004; Parke, 1996) have suggested that fathers may also indirectly affect the child's relationship with the mother. In this sample, we observed a significant association between the Play/Leisure scale and the AQS security score with the mother. This may be interpreted as an indirect effect, if the increased father participation in play and leisure activities with the child does reduce the interactive burden on an employed mother (who is also maintaining her responsibility for household maintenance, etc.). However, correlational data cannot be interpreted directionally and it could as easily be the case that when a child has a secure relationship with the mother, he or she becomes a more attractive playmate and elicits/solicits play with the father more effectively. Only a more intensive and experimental study can address both possible interpretations.

Finally, it is simplistic to think that a father's active participation or even the sharing of child care with his wife always benefits the child. In other studies either no associations were found or (negative) interactive effects have been reported (e.g., Brown et al., 2007; Cox et al., 1992; Easterbrooks \& Goldberg, 1984). Even so, in this sample fathers who shared child-care tasks to a greater extent had children with higher 
AQS security scores. Attachment security is an index of child-parent relationship quality that according to Ainsworth et al. (1978) and Bowlby (1969/1982) develops as a result, at least in part, of sensitive parenting behaviour (see meta-analyses by De Wolff \& van IJzendoorn, 1997; van IJzendoorn \& De Wolff, 1997). So, while we did not directly assess the quality of fathers' interactions, it can be inferred that quality and quantity of involvement were intertwined for this sample (see also Pleck et al., 2004). Again, additional studies that include relevant assessments of interactional quality (e.g., Ainsworth's sensitivity scales; Ainsworth et al., 1978) will be required to consider both quantity and quality of involvement as a support for child attachment security.

Although our findings should be interpreted cautiously due to the modest sample size, these results suggest that fathers' participation in the rearing of their children has value, and that public education and policy in support of fathers' participation is as important as it is for mothers.

Manuscript received 3 November 2008 Revised manuscript accepted 10 February 2009

First published online 19 August 2009

\section{REFERENCES}

Ainsworth, M. D. S. (1967). In Infancy in Uganda (ch. 20). (Available at: http://www. psychology.sunysb.edu/attachment/ainsworth/ainsworth_index - retrieved 2002)

Ainsworth, M. D. S., Blehar, M., Waters, E., \& Wall, S. (1978). Patterns of attachment: A psychological study of the strange situation. Hillsdale, NJ: Lawrence Erlbaum Associates, Inc.

Amâncio, L., \& Wall, K. (2004). Familias e papéis de género: Alguns dados recentes do Family and Gender Survey (ISSP). VIII Congresso Luso-Afro-Brasileiro de ciências sociais. Coimbra. Portugal.

Balancho, L. S. (2004). Ser pai: Transformações intergeracionais na paternidade. Análise Psicológica, 22, 377-386.

Belsky, J. (1984). The determinants of parenting: A process model. Child Development, 55, 83-96.

Bowlby, J. (1982). Attachment and loss. Vol. 1: Attachment (2nd rev. ed.). New York: Basic Books. (Original work published 1969).

Bowlby, J. (1988). A secure base. Parent-child attachment and healthy development. New York: Basic Books.

Bowlby, J. (2002). Cuidados Maternos e Saúde Mental (4th ed.). São Paulo, Brazil: Martins Fontes.

Brown, G., McBride, B. A., Shin, N., \& Bost, K. (2007). Parenting predictors of father-child attachment security: Interactive effects of father involvement and fathering quality. Fathering, 5, 197-219.

Cabrera, N. J., Tamis-LeMonda, C. S., Bradley, R. H., Hofferth, S., \& Lamb, M. E. (2000). Fatherhood in the twenty-first century. Child Development, 71, 127-136.

Caldera, Y. M. (2004). Paternal involvement and infant-father attachment: A Q-set study. Fathering, 2(2), 191-210. 
Cox, M., Owen, M., Henderson, V., \& Margand, N. (1992). Prediction of infant-father and infant-mother attachment. Developmental Psychology, 28, 474-483.

De Wolff, M., \& van IJzendoorn, M. H. (1997). Sensitivity and attachment: A meta-analysis on parental antecedents of infant-attachment. Child Development, 68, 571-591.

Deutsch, F. M. (2001). Equally shared parenting. American Psychological Society, 10(1), 25-28.

Donate-Bartfield, E., \& Passman, R. H. (1985). Attentiveness of mothers and fathers to their baby's cries. Infant Behavior \& Development, 8(4), 385-393.

Easterbrooks, M. A., \& Goldberg, W. A. (1984). Toddler development in the family: Impact of father involvement and parenting characteristics. Child Development, 55, 740-752.

Frosch, C., Mangelsdorf, S. C., \& McHale, J. L. (2000). Marital behavior and the security of preschooler-parent attachment relationships. Journal of Family Psychology, 14(1), 144-161.

Goossens, F. (1987). Maternal employment and day care: Effects on attachment. In L. W. C. Tavecchio \& M. H. van IJzendoorn (Eds.), Attachment in social networks (pp. 135-183). Elsevier Science Publishers.

Grossmann, K., Grossmann, K., Fremmer-Bombik, E., Kindler, H., Scheuerer-Englisch, H., \& Zimmermann, P. (2002). The uniqueness of the child-father attachment relationship: Father's sensitive and challenging play as a pivotal variable in a 16-year longitudinal study. Social development, 11(3), 307-331.

Lamb, M. E. (1977). Father-infant and mother-infant interactions in the first year of life. Child Development, 48, 167-181.

Lamb, M. E. (Ed.), (1987). The father's role: Cross-cultural perspectives. Hillsdale, NJ: Lawrence Erlbaum Associates, Inc.

Lamb, M. E. (Ed.), (2004). The role of the father in child development. Hoboken, NJ: Wiley.

Lamb, M. E., Frodi, M., Hwang, C., \& Frodi, A. (1983). Effects of paternal involvement for mothers and fathers. Child Development, 54, 450-458.

Lamb, M. E., \& Lewis, C. (2004). The development and significance of father-child relationships in two-parent families. In M. E. Lamb (Ed.), The role of the father in child development (pp. 272-306). Hoboken, NJ: Wiley.

Lamb, M. E., \& Tamis-Lemonda, C. S. (2004). The role of the father: An introduction. In M. E. Lamb (Ed.), The role of the father in child development (pp. 1-31). Hoboken, NJ: Wiley.

Main, M., \& Weston, D. R. (1981). The quality of the toddler's relationship to mother and to father: Related to conflict behaviour and the readiness to establish new relationships. Child Development, 52, 932-940.

Marvin, R. S., \& Britner, P. A. (1999). Normative development: The ontogeny of attachment. In J. Cassidy \& P. R. Shaver (Eds.), Handbook of attachment theory: Research and clinical applications (pp. 44-67). New York: Guilford Press.

Monteiro, L., Veríssimo, M., Castro, R., \& Oliveira, C. (2006). Partilha da responsabilidade parental. Realidade ou expectativa? Psychologica, 42, 213-229.

Monteiro, L., Veríssimo, M., Vaughn, B., Santos, A. J., \& Fernandes, M. (2008). Análise do fenómeno de base segura em contexto familiar: as relações Criança/Mãe e Criança/pai. Psicologia, 23(1), 105-125.

Parke, R. D. (1996). Fatherhood. In J. Bruner, M. Cole, \& A. Karmiloff-Smith (Series Eds.), Fatherhood: The developing child. Cambridge, MA: Harvard University Press.

Peitz, G. Fthenakis, W. E., \& Kalicki, B. (2001). Determinants of paternal involvement during the child's third year of life: Childcare tasks versus pleasure activities. Poster presented at the Society for Research in Child Development. Minneapolis, USA.

Pleck, J. H., \& Masciadrelli, B. P. (2004). Paternal involvement by US residential fathers. Levels, sources, and consequences. In M. E. Lamb (Ed.), The role of the father in child development (pp. 222-306). Hoboken, NJ: Wiley. 


\section{0}

Posada, G., Goa, Y., Wu, F., Posada, R., Tascon, M., Schoelmerich, A., et al. (1995a). The secure base phenomenon across cultures: Children's behaviour, mother's preferences and experts concepts. In E. Waters, B. E. Vaughn, G. Posada, \& K. Kondon-Ikemura (Eds.), Caregiving, cultural, and cognitive perspectives on secure base behavior and working models: New growing points of attachment theory and research. Monographs of the Society for Research in the Child Development, 60(2-3), 27-47.

Posada, G., Jacobs, A., Carbonell, G., Alzate, G., Bustamante, M., \& Arenas, A. (1999). Maternal care and attachment security in ordinary and emergency contexts. Developmental Psychology, 35(6), 1379-1388.

Posada, G., Waters, E., Crowell, J. A., \& Lay, K. (1995b). Is it easier to use a secure mother as a secure base? Attachment Q-sort correlates of adult attachment interview. In E. Waters, B. E. Vaughn, G. Posada, \& K. Kondon-Ikemura (Eds.), Caregiving, cultural, and cognitive perspectives on secure base behavior and working models: New growing points of attachment theory and research. Monographs of the Society for Research in the Child Development, 60(2-3), 133-145.

Schaffer, H. R., \& Emerson, P. E. (1964). The development of social attachments in infancy. Monographs of the Society for research in Child development, 29.

Torres, A. (2004). Vida conjugal e o trabalho. Uma perspective sociológica. Oeiras, Portugal: Celta.

van IJzendoorn, M. H., \& De Wolff, M. (1997). In search of the absent father-meta-analyses of infant-father attachment: A rejoinder to our discussants. Child Development, 68, 604-609.

van IJzendoorn, M. H., Vereijken, C. M. J. L., Bakermans-Kranenburg, M. J., \& RiksenWalraven, J. M. (2004). Assessing attachment security with the attachment Q-sort: Metaanalytic evidence for the validity of the observer AQS. Child Development, 75, 1188-1213.

Vaughn, B. E., \& Waters, E. (1990). Attachment behavior at home and in the laboratory: Q-sort observations and strange situation classifications of one-year-olds. Child Development, 61, 1965-1973.

Veríssimo, M., Blicharsky, T., Strayer, F., \& Santos, A. (1995). Vinculação e estilos de comunicação da criança. Análise Psicológica, 13(1-2), 145-155.

Veríssimo, M., Monteiro, L., Vaughn, B. E., Santos, A. J., \& Waters, H. (2005). Co-ordenação entre o modelo interno dinâmico da mãe e o comportamento de base segura dos seus filhos. Análise Psicológica, 23(2), 7-17.

Waters, E. (1995). Appendix A: Attachment Q-set (version 3.0). In E. Waters, B. E. Vaughn, G. Posada, \& K. Kondon-Ikemura (Eds.), Caregiving, cultural, and cognitive perspectives on secure base behavior and working models: New growing points of attachment theory and research. Monographs of the Society for Research in the Child Development, 60(2-3), 234-246.

Waters, E., \& Deane, K. (1985). Defining and assessing individual differences in attachment relationships: Q-methodology and the organization of behaviour in infancy and early childhood. In I. Bretherton \& E. Waters (Eds.), Growing points of attachment theory and research. Monographs of the Society for Research in the Child Development, 50(1-2), 41-65. 
Copyright of European Journal of Developmental Psychology is the property of Psychology Press (UK) and its content may not be copied or emailed to multiple sites or posted to a listserv without the copyright holder's express written permission. However, users may print, download, or email articles for individual use. 